\title{
Original Research \\ Collaboration with pharmacy services in a family practice for the medically underserved
}

\author{
Fallon ENFINGER, Kendall CAMPBELL, James R. TAYLOR. \\ Received (first version): 4-Jul-2009 Accepted: 17-Nov-2009
}

\begin{abstract}
${ }^{*}$
Objectives: Pharmacist-managed collaborative services in a family practice setting are described, and diabetes and hypertension outcomes are assessed.

Methods: Pharmacist-managed clinics, pharmacotherapy consultations, and drug information services are provided for a medically underserved, predominantly African American population. A pharmacy residency director, an ambulatory care pharmacy resident and three PharmD candidate student pharmacists work directly with physicians, nurse practitioners, nurses, and social workers to form an interdisciplinary health care team. Providers utilize pharmacy services through consultations and referrals. Collaboration outcomes were evaluated in twentytwo patients with diabetes and thirty hypertensive patients. Patients were retrospectively followed throughout their history with pharmacy service. Hemoglobin A1c (A1C) was tracked before referral to pharmacy services, 3 to 6 months after, and as the most current measure after at least 6 months. Blood pressure (BP) was observed before pharmacy involvement, 2 to 4 months later, and then currently for at least 4 months with the service. The mean of the most current markers was calculated, and the percent of patients at their goal marker was compared to national averages. Results: Fifty percent of pharmacy service patients met the American Diabetes Association hemoglobin A1c goal of less than $7 \%$ in our evaluation compared to the national mean of $49.8 \%$ overall and $44 \%$ in African Americans. Thirty percent of patients were at their BP goal while $33.1 \%$ of patients without diabetes and $33.2 \%$ of patients with diabetes nationally are at goal.

Conclusion: The medically underserved patients under the care of pharmacy services achieved a higher percentage at their $\mathrm{A} 1 \mathrm{C}$ goal than the national mean. The percentage of patients who achieved their BP goals was comparable to the national average. Increasing utilization of pharmacy services in the family practice setting allows for pharmacists and providers to form a trusted
\end{abstract}

\footnotetext{
*Fallon ENFINGER. PharmD. Assistant Professor. LECOM Bradenton School of Pharmacy, Department of Pharmacy Practice. Bradenton, FL (United States).

Kendall CAMPBELL. MD. Assistant Professor. Community Health and Family Medicine. Assistant Dean for Minority Affairs. University of Florida College of Medicine. Gainesville, FL (United States).

James R. TAYLOR. PharmD, CDE. Clinical Associate Professor. University of Florida College of Pharmacy, Department of Pharmacotherapy and Translational Research. Gainesville, FL (United States).
}

relationship while providing enhanced care and potentially improved outcomes for patients.

Keywords: Poverty. Homeless Persons.

Ambulatory Care. Medication

Therapy Management. Pharmacists. United States.

\section{COLABORACIÓN COM SERVICIOS \\ FARMACÉUTICOS EN UNA CONSULTA DE \\ MEDICINA DE FAMILIA PARA OS \\ MEDICAMENTE SUB-ASISTIDOS}

\section{RESUMEN}

Objetivos: Se describen los servicios colaborativos de farmacia en una consulta de medicina familiar y se evalúan los resultados de diabetes e hipertensión. Métodos: Se proporcionaron consultas gestión de la medicación, de farmacoterapia, y servicios de información sobre medicamentos a una población medicamente sub-atendida, predominantemente de afro-americanos. Un farmacéutico director de prácticas, un residente de farmacia ambulatoria, y tres estudiantes de farmacia trabajaron directamente con los médicos, enfermeras y trabajadores sociales para formar un equipo de salud interdiscipinar. Los proveedores utilizaron los servicios de farmacia mediante consultas y remisiones. Se evaluaron los resultados de la colaboración en 22 pacientes con diabetes y 30 hipertensos. Se siguió retrospectivamente a los pacientes mediante su historia con el servicio de farmacia. Se midió la hemoglobina A1c (A1C) antes de la remisión a los servicios de farmacia, 3 a 6 meses después, y en la mayoría después de al menos 6 meses. Se observó la presión arterial antes de la incorporación en la farmacia, 2 a 4 meses más tarde, y hasta 4 meses después del servicio. Se calculó la media de las mediciones actuales, y se comparó el porcentaje de pacientes en valor ideal con las medias nacionales. Resultados: En nuestra evaluación, $155 \%$ de los pacientes del servicio de farmacia alcanzaron los objetivos de hemoglobina A1c de la American Diabetes Association de menos de $7 \%$ comparados con la media total nacional e $49,8 \%$ y de $44 \%$ en afro-americanos. El 30\% de los pacientes estaban en su presión arterial objetivo mientras que el $33,1 \%$ de los pacientes sin diabetes y el 33,2 de los pacientes con diabetes están en ese objetivo a nivel nacional.

Conclusión: Los pacientes medicamente subasistidos bajo los cuidados de servicios farmacéuticos alcanzaron un porcentaje mayor de control de su objetivo de A1Cque la media nacional. El porcentaje de pacientes que alcanzaron el objetivo de presión arterial era comparable a la 
media nacional. El aumento de la utilización de servicios farmacéuticos en consultas de medicina de familia permite a los farmacéuticos y a los proveedores crear una relación de confianza mientras se proporcionan cuidados avanzados y se mejoran los resultados de los pacientes.

Palabras clave: Pobreza. Personas sin hogar. Atención ambulatoria. Gestión de la medicación. Farmacéuticos. Estados Unidos.

\section{INTRODUCTION}

Primary care settings face multiple challenges in attempting to provide care. Those practices that serve underserved populations are especially challenged not only to provide comprehensive care, but to also provide additional supportive resources to make care possible. Interdisciplinary teams in the primary care setting are a valuable resource in providing those additional supportive resources. Part of the interdisciplinary team that is a necessary component of practice offerings is pharmacy services. The role of the pharmacist has been evolving and growing to include more than just dispensing medicines and providing medication information at the local drug store. There is literature to substantiate the growing need for partnership between community providers and pharmacists and the role pharmacists can play in enhancing patient compliance and outcomes. ${ }^{1}$ Community pharmacy has become an integrated entity and the relationship between the pharmacist and physician has been recognized and is being appreciated and nurtured. Within the evolvement of the role of pharmacy, a shift is not only seen in the community, but in the academic setting as well. As an underserved practice that is part of a large academic center, cross disciplinary care not only provides enhanced offerings for patients but a learning environment for students from multiple disciplines. Pharmacy services are offered in our underserved setting through the academic institution's college of pharmacy and pharmacy staff includes a faculty member, resident and students. This team provides patient education and comanagement through hour long patient visits with real time discussions with the patient's provider. Pharmacy services include medication review, diabetes education and management, lipid, anticoagulation and hypertension management and any other service related to medications. These visits, in contrast to the 15 and 30 minute visits the practitioners spend with the patients, are valuable and focused and provide added time for needed assessment. There is data to show that when pharmacy assists the physician in chronic disease management, better outcomes can be achieved. ${ }^{2-11}$ A lipid study conducted by pharmacists in a clinical setting in South Carolina demonstrated favorable LDL reductions in enrollees where pharmacists played an active role in lipid management. ${ }^{12}$ This model went as far as allowing the pharmacists to prescribe statin therapy and direct changes based on lab review. Our structure permits lab review and recommendation by the pharmacist, however, medication prescribing continues to be by the patient's physician.

In our primary care setting of pharmacy partnership we have seen improved outcomes with respect to chronic disease management. This article will further define this relationship in addition to sharing diabetes and hypertension outcomes of this collaboration. The objective of this study was to compare hemoglobin $\mathrm{A} 1 \mathrm{C}$ and blood pressure measurements before and after pharmacy services were consulted. The post-pharmacy consultation markers were then compared to national goal averages in both disease categories.

\section{METHODS}

\section{Participants}

The family practice clinic averages a total of 12,000 patient visits annually. Sixty-two percent of those visits are within family practice and $38 \%$ are pediatric. Females comprise $61 \%$ of the patient population. The ethnicity breakdown includes $70 \%$ African Americans, 23\% Caucasians, and 7\% Hispanic. The clinic serves a predominantly lowincome and medically underserved patient population. Figure 1 shows that half of the population at the described family practice are Medicaid patients and more than one out of ten patients are self-pay.

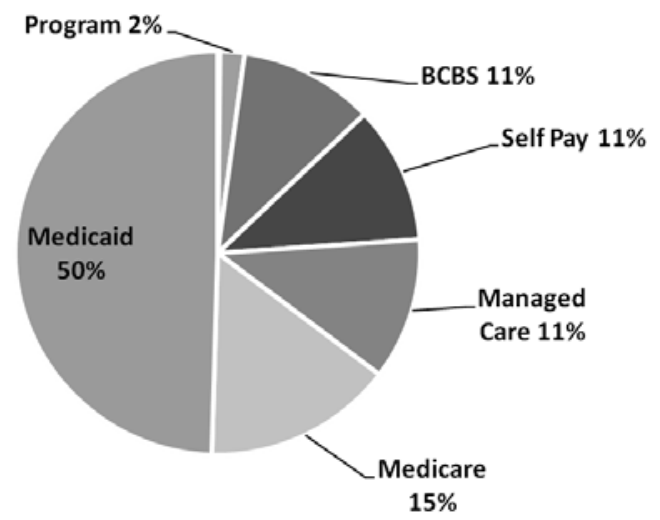

Figure 1. Payor mix of all patients treated at the family practice.

Data was collected on patients with type 2 diabetes and/or hypertensive patients followed by the pharmacy service at the family practice clinic. Patients 18 years or older who were able to be followed prior to and subsequent to referral for pharmacy service by primary providers were included in our evaluation. A1C change was retrospectively tracked for twenty-two patients with type 2 diabetes, and blood pressure change was tracked for thirty patients with type 2 diabetes and/or hypertension ( $83 \%$ of patients evaluated for blood pressure had diabetes).

\section{Intervention}

A pharmacy residency director, an ambulatory care pharmacy resident and three fourth year student 
pharmacists on advanced pharmacy practice experiences (APPEs) work directly with physicians, nurse practitioners, nurses, and social workers to form an interdisciplinary health care team. Family practice providers utilize pharmacy service through pharmacist-run clinic referrals and/or pharmacy team consultations during regular physician visits. Providers may refer patients for a one-hour pharmacy clinic visit when the patient's disease states and/or medications need to be better controlled and require extensive monitoring and/or patient education. Pharmacotherapy management clinics are primarily provided for patients with polypharmacy, new diagnoses, uncontrolled chronic disease, and/or multiple comorbid conditions. Pharmacist-run clinics at this community practice include diabetes, hypertension, hyperlipidemia, anticoagulation, and medication management. The pharmacy service sees the patient for clinic visits that are distinct from their general provider visits. The referred patients are continuously monitored by both the pharmacy service and provider as separate clinic visits. However, all drug therapy and lifestyle recommendations during a pharmacy clinic visit are authorized by and signed off on by the patient's primary provider. Also, a pharmacy clinic visit patient note is added to the patient's chart, thus aiding the continuity of care. Time between both pharmacy and provider clinic visits varies depending upon the status of each patient's disease states. The pharmacy service at our clinic averages approximately 90 one-hour clinic visits per month. Each visit includes:

- Clinical interview focused on disease(s) and medications: Diet/exercise, alcohol/tobacco/illicit drug use, family history, recent medication changes, missed/doubled medication doses (including pharmacy refill histories), adverse effects experienced, food and drug allergies, family history, signs/symptoms of specified disease(s), self-monitoring of blood glucose (SMBG) and/or home blood pressure readings, compliance with daily foot exams and annual eye exams, and thorough medication reconciliation.

- Point of care testing is performed [blood pressure, blood glucose and/or international normalized ratio (INR)]

- Medication counseling

- Disease state and diet/exercise counseling

- Evaluation of medication regimen: drug interactions, adverse events, laboratory values [often fasting lipid panel, A1C, complete or basic metabolic panel (CMP or BMP), thyroid stimulating hormone (TSH), creatine kinase $(\mathrm{CK})$ ]

- Recommendations for changes of medication regimen

- Patient medication list provided for patient and chart

Pharmacy team consultations are operated differently than pharmacy clinic referrals. Consultations are generally obtained when a provider visits the pharmacy office during their patient visit and inquires about a particular drug issue. These medication issues often need to be resolved while the patient remains in the clinic.
However, instances can arise in which the issue must be worked on by the pharmacy team for longer periods of time. Examples of pharmacy consultations include inquiries on drug therapy recommendations for patients on multiple medications or with comborbid conditions, drug side effects, drug interactions, drug indications and contraindications, drug dosing (including renal, hepatic, elderly, and pediatric), pharmacy refill histories, drug formulary management, and patient medication counseling.

The pharmacy service also handles all incoming patient medication concerns and questions (via phone or in the clinic during a provider visit), priorauthorizations (via fax from patient's pharmacy, per provider, or per patient), and prescription refill requests (per patient, per provider, or via pharmacy fax). The pharmacy service averages 40 refills, prior authorizations, and/or medication questions per day.

Additional Pharmacy Services Provided:

- Drug information

- Pharmacotherapy consultation

- Glucose meter demonstration and training

- Medication administration demonstration and training (including insulin, inhalers, nasal sprays, and oral medications)

- Drug sample management and storage within the pharmacy service office

- Drug samples are obtained via pharmaceutical industries and their representatives. Also, patient assistance programs (PAPs) are utilized through the onsite social worker. Drug samples and PAPs are dispensed by the pharmacy when ordered per a provider and medication counseling is performed. Drug samples may be provided to patients in financial hardships, when beginning a new medication in which there are samples available, or when a patient needs a trial of a medication to be changed or newly initiated. PAPs are provided for the patients with financial hardships and are often income restricted.

- Counsel on all psychiatric medications if newly initiated/changed, stopped abruptly before recommended trial period and/or if side effects experienced

- Manage the use of an ambulatory blood pressure monitor to better evaluate resistant hypertension, "white coat" hypertension, fluctuating blood pressures, etc.

- Administrate the Eastside Cares Program as a medication assistance aid for patients during financial hardships

- Patients that cannot afford their prescription copays or USD4 generic prescriptions offered by various retail pharmacies, may be provided with vouchers to obtain these medications for free. Voucher funding is provided through sponsor donations to the family practice clinic. 


\section{Endpoints}

Two primary endpoints were evaluated in this data collection: Hemoglobin A1c (A1C in $\mathrm{mg} / \mathrm{dL}$ ) to assess glycemic control and blood pressure $(\mathrm{mmHg})$. These markers were retrospectively evaluated via patient charts. Patient charts needed to be easily accessible to evaluate each endpoint. Accessibility to charts was based on how long the patient had been at the family practice; the longer a patient's history with the practice, the more likely older chart volumes were located in an unavailable and secure storage unit. A1C was tracked immediately prior to pharmacy referral at the previous physician visit, 3 to 6 months after referral while followed by pharmacy, and at least 6 months later at the most current measure. The mean $\mathrm{A} 1 \mathrm{C}$, mean $\mathrm{A} 1 \mathrm{C}$ change, and percent at the American Diabetes Association (ADA) goal $(\mathrm{A} 1 \mathrm{C}<7 \%$ ) were calculated. ${ }^{13}$ Blood pressure was followed directly prior to pharmacy referral at the previous physician visit, 2 to 4 months after pharmacy referral while followed by pharmacy, and at least 4 months later at the most current measure. The mean blood pressure and percentage at the Seventh Report of the Joint National Commission of hypertension (JNC-7) goal (<140/90mmHg versus $<130 / 80 \mathrm{mmHg}$ for patients with diabetes) were calculated. ${ }^{14}$ The mean percentage at goal for each current marker was then compared to the national averages at goal.

\section{Data Analysis}

No statistical analyses were performed to evaluate the data obtained; only direct comparisons to the national averages as percentages at goal were conducted.

\section{RESULTS}

\section{Hemoglobin A1c}

A total of twenty-two patients were evaluated for glycemic control per A1C. Figure 2 shows the mean A1C for the followed patients with diabetes before referral to pharmacy service was $9.8 \%$; at 3 to 6 months following initiation of pharmacy service the mean was $8.4 \%$; and the most current mean value at an average of 15.5 months (ranging 6 to 50 months) with the service was $7.7 \%$. The overall mean change in $\mathrm{A} 1 \mathrm{C}$ was $2.1 \%$ with $1.5 \%$ at 3 to 6 months and $0.7 \%$ after at least 6 months.

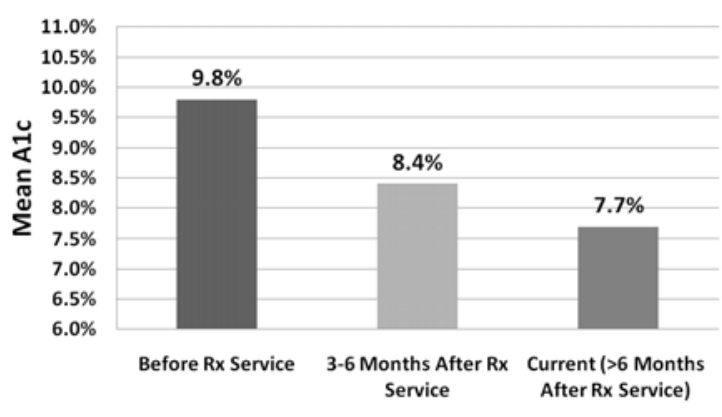

Figure 2. Mean A1c before and after pharmacy referral

$50 \%$ of patients met the ADA recommended A1C goal of less than $7 \%$ at their most current value. ${ }^{13}$
This percent correlates well with the most recent National Health and Nutrition Examination Survey (NHANES) for 1999-2002 data revealing a national average of $49.8 \%$ US adults with diabetes are at goal. This national average is even lower in the African American population at approximately $44 \%$; $70 \%$ of patients treated at the family practice are African American. ${ }^{15}$ (See Table 1)

Table 1: Comparison of percentages of $\mathrm{A} 1 \mathrm{C}$ and blood pressures at goal with our pharmacy service to the national averages

\begin{tabular}{|c|c|c|}
\hline Marker and Goal & $\begin{array}{c}\text { At goal with } \\
\text { Pharmacy } \\
\text { Service }\end{array}$ & $\begin{array}{c}\text { NHANES National } \\
\text { averages at goal in } \\
\text { adults }\end{array}$ \\
\hline $\mathrm{A} 1 \mathrm{C}<7.0 \%$ & $50 \%$ & $\begin{array}{c}49.8 \%(44 \% \text { in African } \\
\text { Americans) }\end{array}$ \\
\hline $\begin{array}{c}\mathrm{BP} \\
<140 / 90 \mathrm{mmHg} \text { or } \\
<130 / 80 \mathrm{mmHg}\end{array}$ & $30 \%$ & $\begin{array}{c}33.1 \%(<140 / 90 \mathrm{mmHg}) \\
33.2 \%(<130 / 80 \mathrm{mmHg})\end{array}$ \\
\hline
\end{tabular}

\section{Blood Pressure}

Thirty patients were evaluated for blood pressure control. $85 \%$ of blood pressure evaluations were performed in patients with diabetes who were at a goal of less than $130 / 80 \mathrm{mmHg}$ per JNC-7 guidelines. The remaining $15 \%$ of blood pressure evaluations were at the less than $140 / 90 \mathrm{mmHg}$ goal. ${ }^{14}$ Figure 3 shows the mean blood pressure before pharmacy service, at $158 / 90 \mathrm{mmHg}$; 2 to 4 months after initiating the service, the mean was $128 / 81 \mathrm{mmHg}$; and at least 4 months following the use of pharmacy services, the most current mean blood pressure was calculated at $132 / 78 \mathrm{mmHg}$. Thirty percent of patients were at their blood pressure goal at the most current level measured at an average of 11.1 months (ranging 4 to 30 months) after initiating pharmacy services. Nationally, 33.1\% of patients without diabetes and $33.2 \%$ of patients with diabetes have met their blood pressure goal per NHANES 1999-2004. ${ }^{16}$ (See Table 1)

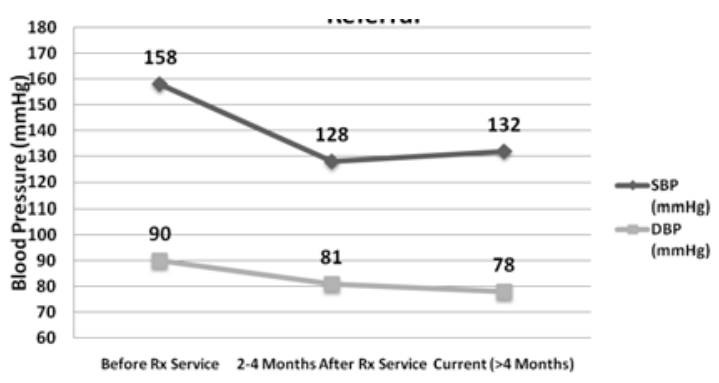

Figure 3. Mean BP before and after pharmacy referral

\section{DISCUSSION}

The most current best practices in many of the chronic diseases managed in the primary care setting, especially diabetes and hypertension, require utilization of polypharmacy. ${ }^{13,14} \mathrm{~A}$ collaborative approach may be needed for the management of multiple medications and these chronic illnesses, especially in a medically underserved patient population. Recent supportive data in a similar practice setting as ours adhered to ADA recommendations. Pharmacy medication 
management significantly improved glycemic control while maintaining weight and blood pressure. ${ }^{10}$ The purpose of our article is to provide a description of an interdisciplinary model incorporating pharmacy services into the medical management of chronic disease states within a unique family practice setting.

According to a 2004 national American Society of Health-System Pharmacists (ASHP) survey of ambulatory care pharmacy practice, the roles and responsibilities of pharmacists are continuously evolving, especially in the Veterans Affairs (VA) system. Over $50 \%$ of the organizations surveyed reported pharmacist-run medication management programs. $^{8} \quad$ Multiple similar models of pharmaceutical care services have been implemented and show promising outcomes that have been described in the literature..$^{2-11}$ In a nonrandomized, prospective VA trial of a clinical pharmacist-managed diabetes clinic, a significant improvement was seen in $\mathrm{A} 1 \mathrm{C}$ from a mean of $10.3 \%$ to $6.9 \%$ over 9 to 12 months $(p<0.001)$. Secondary endpoints of systolic and diastolic blood pressure along with LDL were also reduced $(p<0.001) .^{3}$ The Asheville Project, based out of North Carolina, offered a community-based pharmacy diabetes program in collaboration with physicians. Short-term and long-term clinical outcomes showed significant improvement in A1C values, sick days used were reduced, and employers saved on insurance expenditures. ${ }^{4,5}$ Two trials, one retrospective and one observational, of patients involved in a diabetes management program under a collaborative practice agreement, showed a significant reduction in $\mathrm{A} 1 \mathrm{C}$ and blood pressure, increased the percentage of patients at the ADA's A1C goal, and improved adherence to daily aspirin therapy. ${ }^{7,11}$ We have also provided data on clinical outcomes of glycemic and blood pressure control under the umbrella of a pharmacy referral system. Achievement of outcomes were obtained through detailed interviews, patient education, medication reviews, laboratory reviews, and recommended dosing changes. Our project was carried out retrospectively and was reliant on charts for review. Accessibility to charts limited the number of patients observed. The longer a patient's history with the practice, the more likely older chart volumes were located in an unavailable and secure storage unit. Discrepancies in documentation, as well as, variability in frequency of laboratory testing should be considered. Various styles of documentation and vital sign attainment between health care workers (i.e. physician, nurses, medical assistants) in a single patient chart may produce discrepancies in the outcome markers observed. Also, laboratory testing frequency varies depending on patient-specific disease state control and patient willingness/affordability to obtain the recommended labs. Although the blood pressure data was not an improvement over the national averages at goal, it was comparable and reflects an underserved community. Measurement bias due to multiple different health care workers obtaining blood pressures, as decribed above, may have skewed collected data. Also, patients' diabetes or hypertension pharmacotherapy regimens, as well as years with each disease, were not addressed. The time from most current marker obtained and the beginning of pharmacy services was highly variable at 4 to 30 months (11.1 month mean) for blood pressure values and 6 to 50 months (15.5 month mean) for $\mathrm{A} 1 \mathrm{C}$ values. This variability was attributable to an extensive history with the pharmacy service and/or a low clinic appointment show rate. This current value was obtained in an attempt to reflect the maintainability of the health outcome measures. More detailed tracking of the disease markers throughout the patients' history with pharmacy service could have altered the outcomes observed. Our data was compared to national averages, as was a previous trial which attained treatment goals more often than the national average and improved retinal and microalbumin screening rates.

The primary goal of a pharmacy partnership in the family practice setting is to improve the health outcomes of our patients. Our data suggests success within this partnership to serve a medically underserved community and points us in the direction of multidisciplinary chronic disease state management models as a mainstay in primary care. Pharmacy services in the family practice setting allow for more intense counseling on medications while providers are able to focus on patients' other health concerns.

\section{CONCLUSIONS}

The medically underserved patients under the care of pharmacy services achieved a higher percentage at their hemoglobin A1c goal than the national mean. The percentage of patients who achieved their blood pressure goals was comparable to the national average at goal. Increasing utilization of pharmacy services in the family practice setting allows for pharmacists and providers to form a trusted relationship that broadens each practitioner's knowledge while providing enhanced care and potentially improved outcomes for patients.

\section{CONFLICT OF INTEREST}

No conflicts of interests are reported and this study was not funded.

\section{References}

1. Petty D. Drugs and professional interactions: the modern day pharmacist. Heart. 2003;89(Suppl III):ii31-ii32.

2. Anaya JP, Rivera JO, Lawson K, Garcia J, Luna J, Ortiz M. Evaluation of pharmacist-managed diabetes mellitus under a collaborative drug therapy agreement. Am J Health-Syst Pharm. 2008;65:1841-1845. 
3. Cioffi ST, Caron MF, Kalus JS, Hill P, Buckley TE. Glycosylated hemoglobin, cardiovascular, and renal outcomes in a pharmacist-managed clinic. Ann Pharmacother. 2004;38:771-775.

4. Cranor CW, Bunting BA, Christensen DB. The Asheville Project: long-term clinical and economic outcomes of a community pharmacy diabetes care program. J Am Pharm Assoc. 2003;43:173-184.

5. Cranor CW, Christensen DB. The Asheville Project: short-term outcomes of a community pharmacy diabetes care program. J Am Pharm Assoc. 2003;43:149-159.

6. Isetts BJ, Brown LM, Schondelmeyer SW, Lenarz LA. Quality Assessment of a Collaborative Approach for Decreasing Drug-Related Morbidity and Achieving Therapeutic Goals. Arch Intern Med. 2003;163:1813-1820.

7. Kiel PJ, McCord AD. Pharmacist impact on clinical outcomes in a diabetes disease management program via collaborative practice. Ann Pharmacother. 2005;39:1828-1832.

8. Knapp KK, Okamoto MP, Black BL. ASHP survey of ambulatory care pharmacy practice in health systems -2004 . Am J Health-Syst Pharm. 2005;62:274-284.

9. Morello CM, Zadvorny EB, Cording MA, Suemoto RT, Skog J, Harari A. Development and clinical outcomes of pharmacist-managed diabetes care clinics. Am J Health-Syst Pharm. 2006;63:1325-1231.

10. Nkansah NT, Brewer JM, Connors R, Shermock KM. Clinical outcomes of patients with diabetes mellitus receiving medication management by pharmacists in an urban private physician practice. Am J Health-Syst Pharm. 2008;65:145149.

11. Ragucci KR, Fermo JD, Wessell AM, Chumney ECG. Effectiveness of Pharmacist-Administered Diabetes Mellitus Education and Management Services. Pharmacotherapy. 2005;25(12):1809-1816.

12. Till T, Voris J, Horst J. Assessment of clinical pharmacist management of lipid-lowering therapy in the primary care setting. J Manag Care Pharm 2003;9(3):269-273.

13. American Diabetes Association. Standards of medical care in diabetes - 2009. Diabetes Care. 2009;32(Suppl 1):S1361.

14. Chobanian AV, Bakris GL, Black HR, Cushman WC, Green LA, Izzo JL, Jones DW, Materson BJ, Oparil S, Wright JT, Roccella EJ, and the National High Blood Pressure Education Program Coordinating Committee. The Seventh Report of the Joint National Committee on Prevention, Detection, Evaluation, and Treatment of High Blood Pressure: the JNC 7 report. JAMA. 2003;289:2560-2572

15. Resnick HE, Foster GL, Bardsley J, Ratner RE. Achievement of American Diabetes Association clinical practice recommendations among US adults with diabetes, 1999-2002. The National Health and Nutrition Examination Survey. Diabetes Care. 2006;29:531-537.

16. Ong KL, Cheung BMY, Man YB, Lau CP, Lam KSL. Prevalence, Awareness, Treatment, and Control of Hypertension Among United States Adults 1999-2004. Hypertension. 2007;49:69-75.

\section{Welcome to the $16^{\text {th }}$ ISPW!}
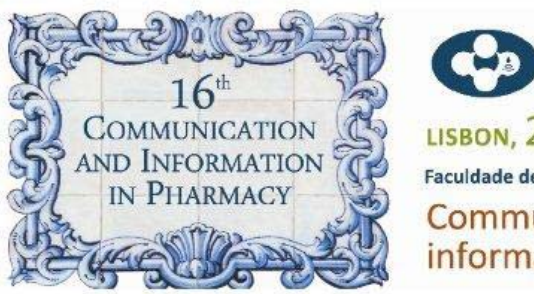

LISBON, 23rd $/ 26^{\text {th }}$ AUGUST 2010

Faculdade de Farmácia da Universidade de Lisboa

Communication and

information in pharmacy

This is a preliminary short announcement for the $16^{\text {th }}$ ISPW

Host Institution and Venue

Faculty of Pharmacy, University of Lisbon, Portugal

Dates

$23^{\text {rd }}$ to $26^{\text {th }}$ August 2010

Key note Speakers and further information soon to be announced at

www.ff.ul.pt/16ISPW

For any inquiries, please use the following email address: 16 ISPW@ff.ul.pt

Hope to have you here in Summer 2010! 